\title{
Breast Osteosarcoma 29 Years after Radiation Therapy for Epithelial Breast Cancer
}

\author{
Nwabundo Nwankwo Aram Barbaryan Alaa M. Ali Nasir Hussain \\ Raya Saba Suartcha Prueksaritanond Aibek E. Mirrakhimov \\ Teresita Zdunek Nora Bucher \\ Saint Joseph Hospital, Department of Internal Medicine, Chicago, Ill., USA
}

\section{Key Words}

Breast osteosarcoma $\cdot$ Radiation therapy $\cdot$ Epithelial breast cancer

\begin{abstract}
Radiation therapy has a solid role in the management of breast adenocarcinoma. It significantly reduces the rates of disease recurrence. Nevertheless, radiation therapy is not without side effects and patients who have undergone breast irradiation are at increased risk for lung disease, sarcomas, acute leukemia and esophageal cancer. We present a case of radiation-induced breast osteosarcoma 29 years after radiation therapy and lumpectomy for breast adenocarcinoma. The patient had several disease recurrences after surgical resection and was found to have pulmonary metastases.

(c) 2013 S. Karger AG, Basel
\end{abstract}

\section{Introduction}

Radiation therapy has a solid role in the management of breast adenocarcinoma. It significantly reduces the rates of disease recurrence [1]. Nevertheless, radiation therapy is not without side effects and patients who have undergone breast irradiation are at increased risk for lung disease, sarcomas, acute leukemia and esophageal cancer $[2,3]$. We present a case of radiation-induced breast osteosarcoma 29 years after radiation therapy for breast adenocarcinoma. 
Nwankwo et al.: Breast Osteosarcoma 29 Years after Radiation Therapy for Epithelial Breast Cancer

\section{Case Presentation}

We present the case of an 87-year-old African American female with a past medical history of right breast adenocarcinoma diagnosed in 1989. At that time, the patient underwent partial mastectomy, axillary lymph node dissection and radiation therapy. The patient had yearly surveillance and diagnostic mammograms with no evidence of disease recurrence. Her past medical history is also significant for hypertension and type 2 diabetes mellitus. The patient's family history is significant for breast cancer in her sister at the age of 40 years and hypertension in both of her parents. The patient was using metformin, lowdose aspirin, lisinopril and hydrochlorothiazide.

In October 2011, a 10-cm tender right breast mass was noted by the patient. She subsequently underwent modified radical mastectomy of the right breast after thorough medical evaluation of the mass (fig. 1). The pathology report was consistent with chondroblastic osteosarcoma (fig. 2). The tumor stained positive for vimentin and negative for cytokeratin.

Eight months later, the patient had a recurrence of the lesion and a re-excision was performed with clear margins. A pathology report of the recurrent breast mass was consistent with breast osteosarcoma. Eight months after the second surgery, the patient started having fatigue and dry cough. A computed tomography of the chest was performed and showed bilateral pulmonary nodules suspicious for a malignancy (fig. 3). A biopsy of the nodules revealed metastatic osteosarcoma (fig. 4). The patient was started on liposomal doxorubicin chemotherapy. Transthoracic echocardiography was performed prior to doxorubicin initiation, given potential cardiotoxic effects of doxorubicin. Transthoracic echocardiography showed a normal heart function. The patient tolerated chemotherapy well and is scheduled for the next visit in 2 months.

\section{Discussion}

Breast osteosarcoma is a rare malignant tumor arising from the connective tissue. It accounts for less than $1 \%$ of breast malignancies [4]. Bloodstream is the most important route for metastases of breast osteosarcoma with lungs, bone and liver being the most common sites involved [5]. Breast osteosarcoma is typically seen in middle- to old-age individuals compared to skeletal osteosarcoma, which is typically seen in a younger population.

Ionizing radiation is considered to be a leading risk factor for the development of breast osteosarcoma and other histological types of breast sarcomas [6]. It is typically seen in patients who have undergone radiation therapy that included the chest area (e.g. breast adenocarcinoma, lymphoma, etc.). By definition, breast osteosarcoma must arise in the same field $[6,7]$. The risk of breast osteosarcoma is present even 20 years after radiation therapy [8]. The patient presented in this case report experienced the disease 29 years after radiation therapy.

Histologically, the tumor is characterized by the presence of malignant spindle-shaped cells, which represent the formation of malignant osteoid. The tumor cells are positive for vimentin, smooth muscle actin and S-100 [5].

Breast osteosarcoma has an aggressive course with high rates of tumor recurrence. The management of breast osteosarcoma differs significantly from treatment of breast adenocarcinoma. Surgical management is the mainstay of treatment for breast osteosarcoma [5]. Surgical excision was the most important predictor for long-term survival in 28 patients with different histological types of breast sarcomas [9]. Breast irradiation is controversial, 
especially in settings of radiation-associated breast osteosarcoma, since these patients are at increased risk for early complications of radiation, such as soft tissue damage, pneumonitis and rib fractures [6]. There is no consensus regarding the role of chemotherapy in patients with radiation-induced breast osteosarcoma [10]. The role of chemotherapy is controversial and consultation with an oncologist is highly recommended. Doxorubicin either alone or in combination with ifosfamide can be considered for chemotherapy in selected patients.

\section{Conclusion}

Breast osteosarcoma is a rare breast malignancy with an aggressive course. The most important risk factor for the occurrence of breast osteosarcoma is chest field irradiation. It is necessary to keep in mind that the radiation therapy-associated risk for breast osteosarcoma persists for more than 20 years. The management of breast osteosarcoma is surgical. The role of chemotherapy is not well established, and radiation therapy is controversial.

\section{Disclosure Statement}

The authors have no conflicts of interest.

\section{References}

1 Fisher B, Anderson S, Bryant J, Margolese RG, Deutsch M, Fisher ER, Jeong JH, Wolmark N: Twenty-year follow-up of a randomized trial comparing total mastectomy, lumpectomy, and lumpectomy plus irradiation for the treatment of invasive breast cancer. N Engl J Med 2002;347:1233-1241.

-2 Berrington de Gonzalez A, Curtis RE, Gilbert E, Berg CD, Smith SA, Stovall M, Ron E: Second solid cancers after radiotherapy for breast cancer in SEER cancer registries. Br J Cancer 2010;102:220-226.

-3 Cole M, Strair R: Acute myelogenous leukemia and myelodysplasia secondary to breast cancer treatment: case studies and literature review. Am J Med Sci 2010;339:36-40.

4 McGowan TS, Cummings BJ, O'Sullivan B, Catton CN, Miller N, Panzarella T: An analysis of 78 breast sarcoma patients without distant metastases at presentation. Int J Radiat Oncol Biol Phys 2000;46:383-390.

5 Gull S, Patil P, Spence RA: Primary osteosarcoma of breast. BMJ Case Rep 2011, DOI: 10.1136/bcr.03.2011.4015.

6 Sheth GR, Cranmer LD, Smith BD, Grasso-Lebeau L, Lang JE: Radiation-induced sarcoma of the breast: a systematic review. Oncologist 2012;17:405-418.

7 Murray EM, Werner D, Greeff EA, Taylor DA: Postradiation sarcomas: 20 cases and a literature review. Int J Radiat Oncol Biol Phys 1999;45:951-961.

8 Mery CM, George S, Bertagnolli MM, Raut CP: Secondary sarcomas after radiotherapy for breast cancer: sustained risk and poor survival. Cancer 2009;115:4055-4063.

-9 Shabahang M, Franceschi D, Sundaram M, Castillo MH, Moffat FL, Frank DS, Rosenberg ER, Bullock KE, Livingstone AS: Surgical management of primary breast sarcoma. Am Surg 2002;68:673-677.

10 Casali PG, Blay JY: Soft tissue sarcomas: ESMO Clinical Practice Guidelines for diagnosis, treatment and follow-up. Ann Oncol 2010;21(suppl 5):v198-v203. 


\section{Case Reports in Oncology}

\begin{tabular}{l|l}
\hline Case Rep Oncol 2013;6:367-372 \\
\hline DOI: 10.1159/000353888 & $\begin{array}{l}\text { ○ 2013 S. Karger AG, Basel } \\
\text { www.karger.com/cro }\end{array}$ \\
\hline
\end{tabular}

Nwankwo et al.: Breast Osteosarcoma 29 Years after Radiation Therapy for Epithelial Breast Cancer

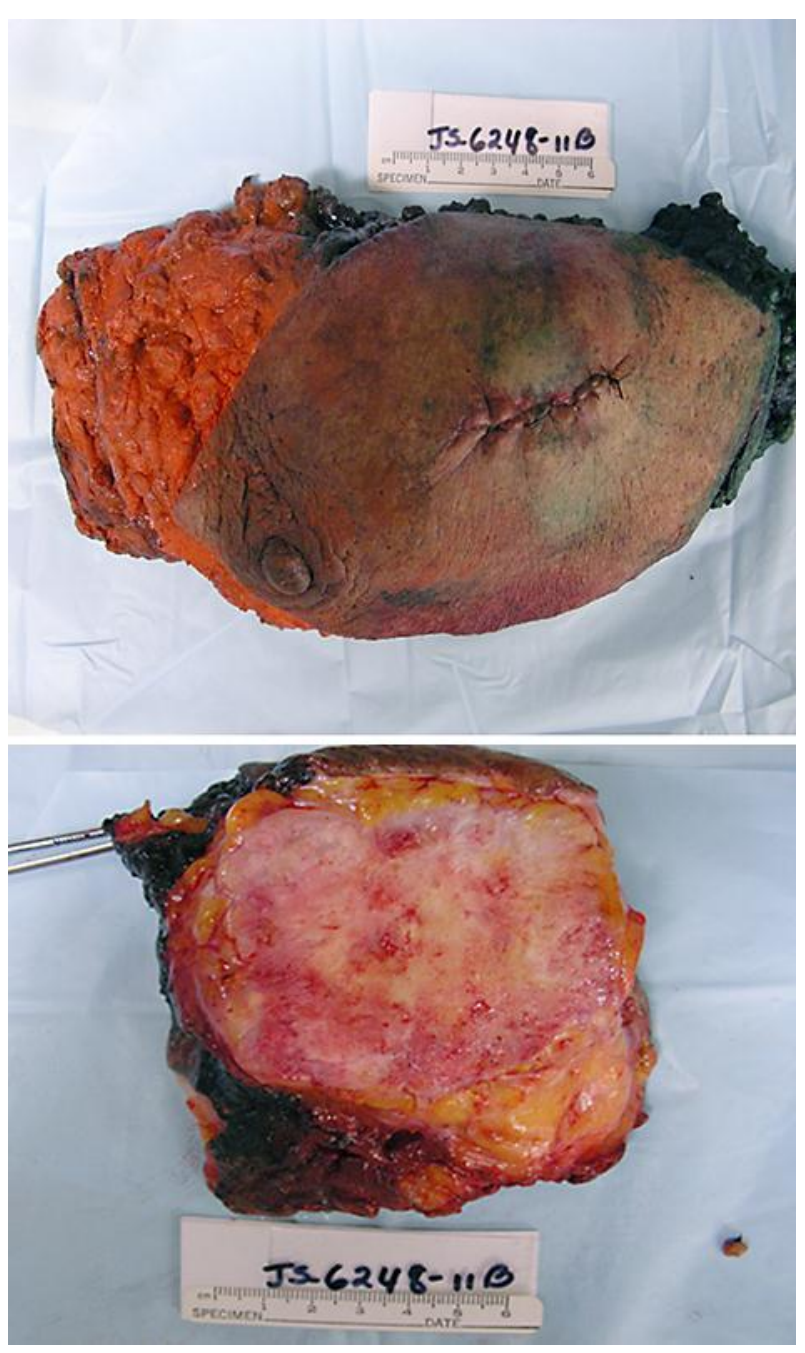

Fig. 1. Gross pathology of the right breast osteosarcoma. 


\section{Case Reports in Oncology}

\begin{tabular}{l|l}
\hline \multicolumn{2}{l}{ Case Rep Oncol 2013;6:367-372 } \\
\hline DOI: $10.1159 / 000353888$ & $\begin{array}{l}\text { C 2013 S. Karger AG, Basel } \\
\text { www.karger.com/cro }\end{array}$ \\
\hline
\end{tabular}

Nwankwo et al.: Breast Osteosarcoma 29 Years after Radiation Therapy for Epithelial Breast Cancer

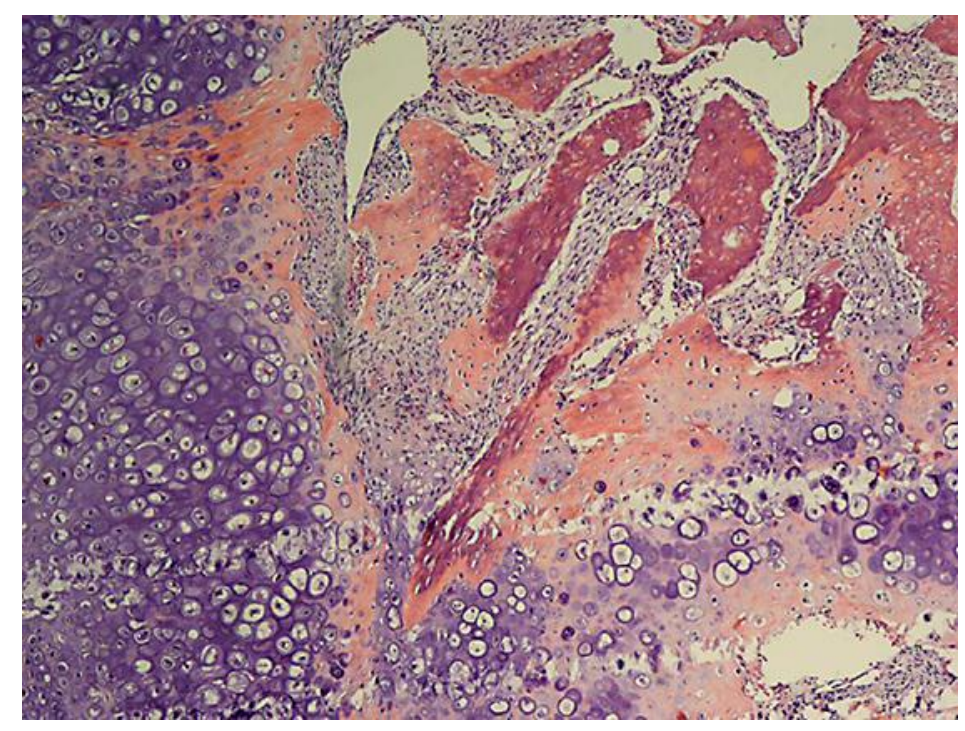

Fig. 2. Pathology reports showing spindle-shaped cells with irregular nuclei and perinuclear halos forming malignant osteoid consistent with osteosarcoma.

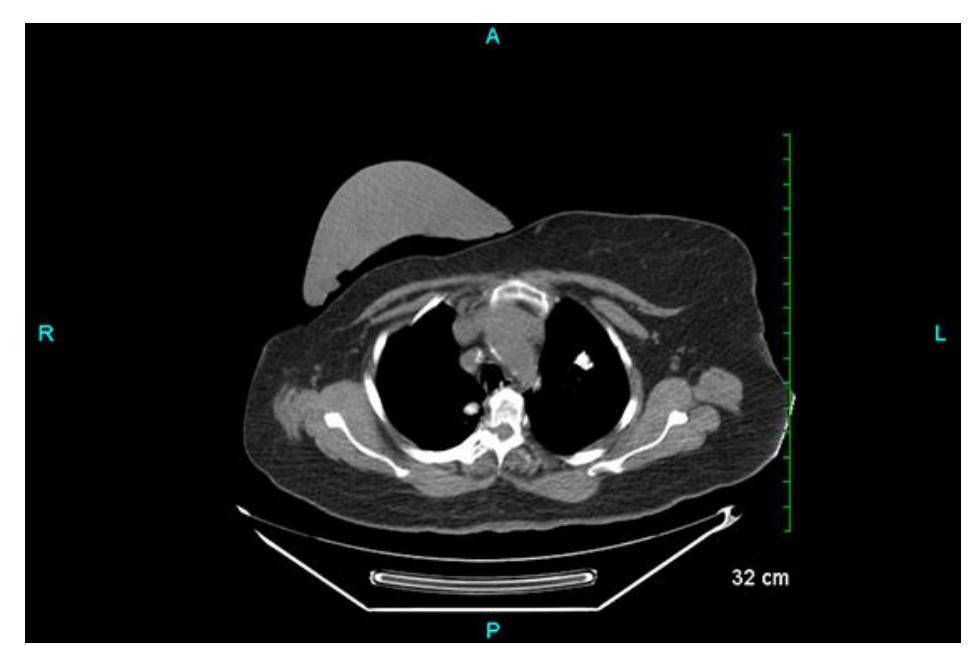

Fig. 3. Chest computed tomography showing bilateral pulmonary nodules. 


\section{Case Reports in Oncology}

\begin{tabular}{l|l}
\hline Case Rep Oncol 2013;6:367-372 \\
\hline DOI: $10.1159 / 000353888$ & $\begin{array}{l}\text { C 2013 S. Karger AG, Basel } \\
\text { www.karger.com/cro }\end{array}$ \\
\hline
\end{tabular}

Nwankwo et al.: Breast Osteosarcoma 29 Years after Radiation Therapy for Epithelial Breast Cancer

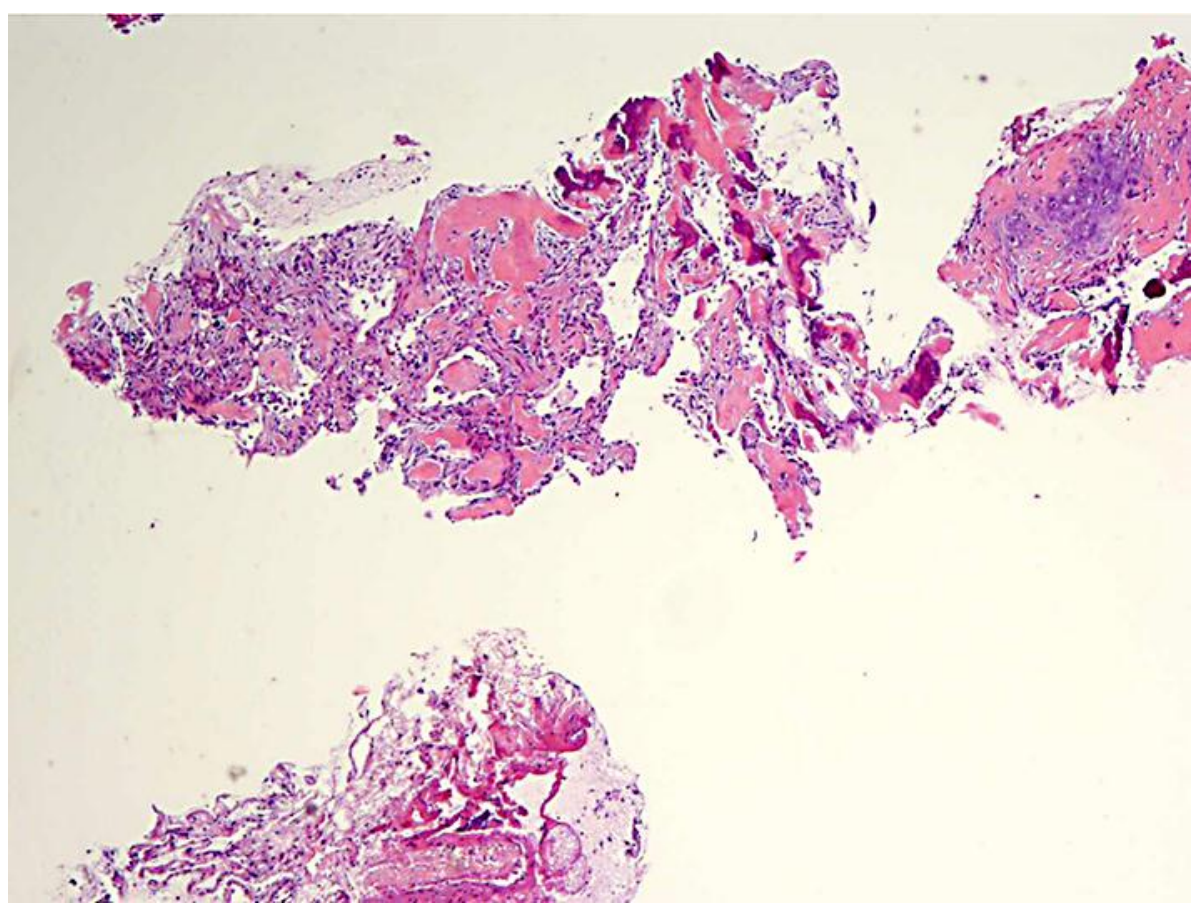

Fig. 4. The tumor forms islands of osteoid and cartilage. The cartilaginous areas show hypercellularity, atypical chondrocytes and single cells with hyperchromasia and high nuclear to cytoplasm ratio consistent with metastatic osteosarcoma to the lungs. 